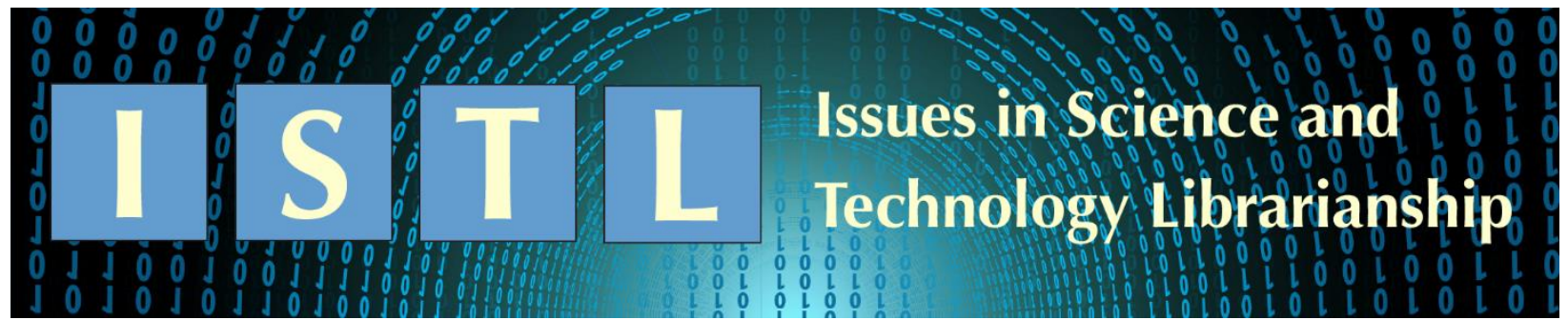

\title{
Cleaning Collections Data Using OpenRefine
}

\author{
Elizabeth Sterner, MLIS, MS \\ Health and Human Services Librarian \\ Assistant Professor \\ Governors State University \\ esterner@govst.edu
}

Collection maintenance, including weeding, is a key component of my position as an academic science librarian. In an ideal world we receive perfect data that are clean and ready to use. But unfortunately, that is not always the case. In large deselection projects you might receive holdings and circulation records in separate files which, once combined, may contain many undesired duplicated line items. I will demonstrate how you can effectively and quickly use the facet row feature in OpenRefine to deduplicate data. The benefit of this method is that you select which of the duplicated items will be kept and which will be deleted. Once OpenRefine is downloaded and opened, you work in a web user interface to upload your data, clean and transform the data, and then download from the browser to a CSV file in Excel. With practice, I have found that this only takes a few minutes for thousands of line items, and ensures I am able to select the data I want.

\section{Why OpenRefine?}

I choose to use OpenRefine, an open source tool available on GitHub, because it is free, easy to learn and use, and allows for the selection of a union of rows after applying facets and filters. OpenRefine offers a platform for data management; and users, including non-programmers, do not need to know how to code to clean and transform data. With OpenRefine, I can ensure I am deleting specific line items while confirming I am keeping preferred line items.

\section{Method}

Basically, I divide my data into numerous sets, and then I select the union of desired sets. I have used this method during large weeding projects when I received two Excel files.

In this example, I received the data necessary for the deselection process in two different files. The first file of all holdings included the following fields: DISPLAY_CALL_NO, TITLE, PUB_PLACE, PUBLISHER, PUBLISHER_DATE, ITEM_BARCODE, and LOCATION_ID (Figure 1). 


\begin{tabular}{|l|l|l|l|c|c|c|}
\hline DISPLAY_CALL_NO & TITLE & PUB_PLACE & PUBLISHER & $\begin{array}{c}\text { PUBLISHER } \\
\text { _DATE }\end{array}$ & ITEM_BARCODE & $\begin{array}{c}\text { LOCATION_ } \\
\text { ID }\end{array}$ \\
\hline RT31 .A25 & Book of Nursing & Amherst, N.Y. & Publisher A & 2018 & 123456 & 1 \\
\hline HV91 .H424 & Social Work Book & Chicago, IL & Publisher B & 2016 & 987654 & 2 \\
\hline QD33 .S73 & Chemistry & New York, NY & Publisher C & 2015 & 345678 & 2 \\
\hline QH442 .G4462009 & Genetic Engineering & Detroit, MI & Publisher B & 2009 & & 1 \\
\hline
\end{tabular}

Figure 1: Example of records holdings.

The second file of items circulated included the following fields: DISPLAY_CALL_NO, TITLE, PUBLISHER, PUBLISHER_DATE, ITEM_BARCODE, HISTORICAL_CHARGES, and LastOfCHARGE_DATE (Figure 2).

\begin{tabular}{|l|l|l|c|c|c|c|}
$\begin{array}{l}\text { DISPLAY_CALL } \\
\text { NO }\end{array}$ & TITLE & PUBLISHER & $\begin{array}{c}\text { PUBLISHER_ } \\
\text { DATE }\end{array}$ & $\begin{array}{c}\text { ITEM_BARCOD } \\
\text { E }\end{array}$ & $\begin{array}{c}\text { HISTORICAL } \\
\text { CHARGES }\end{array}$ & $\begin{array}{c}\text { LastOfCHAR } \\
\text { GE_DATE }\end{array}$ \\
\hline RT31 .A25 & Book of Nursing & Publisher A & 2018 & 123456 & 1 & 20 -Aug-19 \\
\hline QD33 .S73 & Chemistry & Publisher C & 2015 & 345678 & 3 & $10-$ May-18 \\
\hline
\end{tabular}

Figure 2: Example of circulation statistics.

\section{Combining Files}

Before I can go any further, I want to combine the two data files into one file. I want all the information available in one file to increase my efficiency while in the stacks reviewing the collection, and to provide one file of data to the faculty members of my liaison areas. I combine the data with some simple manipulations in Excel. First, I make sure that all columns match (Figure 3). Then I copy and paste the smaller circulation file to the significantly larger file of holdings (Figure 4). The smaller circulation files typically holds approximately 200-3,000 lines of data. The larger files of holdings hold between 5,000-20,000 lines of data.

\begin{tabular}{|c|c|c|c|c|c|c|c|c|}
\hline $\begin{array}{l}\text { DISPLAY_- } \\
\text { CALL_NO }\end{array}$ & TITLE & PUB_PLACE & PUBLISHER & $\begin{array}{c}\text { PUBLISHER } \\
\text { _DATE }\end{array}$ & ITEM_BARCODE & LOCATION_ID & & \\
\hline RT31.A25 & Book of Nursing & $\begin{array}{l}\text { Amherst, } \\
\text { N.Y. }\end{array}$ & Publisher A & 2018 & 123456 & 1 & & \\
\hline HV91.H42. & Social Work Book & Chicago, IL & Publisher B & 2016 & 987654 & 2 & & \\
\hline QD33.S73 & Chemistry & New York, $\mathrm{N}$ & Publisher C & 2015 & 345678 & 2 & & \\
\hline QH442.G4 & Genetic Engineering & Detroit, MI & Publisher B & 2009 & & 1 & & \\
\hline $\begin{array}{l}\text { DISPLAY_- } \\
\text { CALL_NO }\end{array}$ & TITLE & PUB_PLACE & PUBLISHER & $\begin{array}{c}\text { PUBLISHER } \\
\text { _DATE }\end{array}$ & ITEM_BARCODE & LOCATION_ID & $\begin{array}{c}\text { HISTORICA } \\
\text { L_CHARGE } \\
\text { S }\end{array}$ & $\begin{array}{c}\text { LastOfCHARG } \\
\text { E_DATE }\end{array}$ \\
\hline RT31.A25 & Book of Nursing & & Publisher A & 2018 & 123456 & & 1 & 20-Aug-19 \\
\hline QD33 .S73 & Chemistry & & Publisher C & 2015 & 345678 & & 3 & 10-May-18 \\
\hline
\end{tabular}

Figure 3: Mismatch of combined data.

\begin{tabular}{|c|c|c|c|c|c|c|c|c|}
\hline $\begin{array}{l}\text { DISPLAY_- } \\
\text { CALL_NO }\end{array}$ & TITLE & PUB_PLACE & PUBLISHER & $\begin{array}{c}\text { PUBLISHER } \\
\text { _DATE }\end{array}$ & ITEM_BARCODE & LOCATION_ID & $\begin{array}{c}\text { HISTORICAL_ } \\
\text { CHARGES }\end{array}$ & \begin{tabular}{|l} 
LastOfCHAR \\
GE_DATE
\end{tabular} \\
\hline RT31.A25 & Book of Nursing & Amherst, & Publisher A & 2018 & 123456 & 1 & & \\
\hline HV91.H42. & Social Work Book & Chicago, IL & Publisher B & 2016 & 987654 & 2 & & \\
\hline QD33.S73 & Chemistry & New York, N & Publisher C & 2015 & 345678 & 2 & & \\
\hline QH442.G4 & Genetic Engineering & Detroit, MI & Publisher B & 2009 & & 1 & & \\
\hline RT31.A25 & Book of Nursing & & Publisher A & 2018 & 123456 & & 1 & 20-Aug-19 \\
\hline QD33 .S73 & Chemistry & & Publisher C & 2015 & 345678 & & 3 & 10-May-18 \\
\hline
\end{tabular}

Figure 4: Example of combined data with duplicates. 
This first step creates duplicates of items, books in this case, that had been previously checked out. This is not something that I want to deduplicate by hand. I opt to use OpenRefine so that I can control which duplicate line item I am deleting. OpenRefine provides the functionality of the facets for my desired data cleanup. After downloading and opening OpenRefine, I create a project (Figure 5).

OpenRefine A power tool for working with messy data.

\begin{tabular}{|c|c|c|}
\hline Create Project & \multicolumn{2}{|c|}{ Create a project by importing data. What kinds of data files can I import? } \\
\hline \multirow{7}{*}{$\begin{array}{l}\text { Open Project } \\
\text { Import Project } \\
\text { Language Settings }\end{array}$} & \multicolumn{2}{|c|}{$\begin{array}{l}\text { TSV, CSV, *SV, Excel (.xls and .XIsx), JSON, XML, RDF as XML, and Google Data documents are all supported. Support for other formats can be added with } \\
\text { OpenRefine extensions. }\end{array}$} \\
\hline & Get data from & Locate one or more files on your computer to upload: \\
\hline & This Computer & Choose Files No file chosen \\
\hline & Web Addresses (URLs) & Next $"$ \\
\hline & Clipboard & \\
\hline & Data Package (JSON URL) & \\
\hline & Database & \\
\hline
\end{tabular}

Figure 5: Screenshot of creating a project in OpenRefine.

\section{Selecting Non-Duplicated Items}

My first step is to select items which are not duplicated. That is, they are in the collection, but they have not been checked out. To do this, I need to transform the data into "Text" first. I select "Edit cells," "Common transformations" and "To text" under ITEM_BARCODE (Figures 6-7).

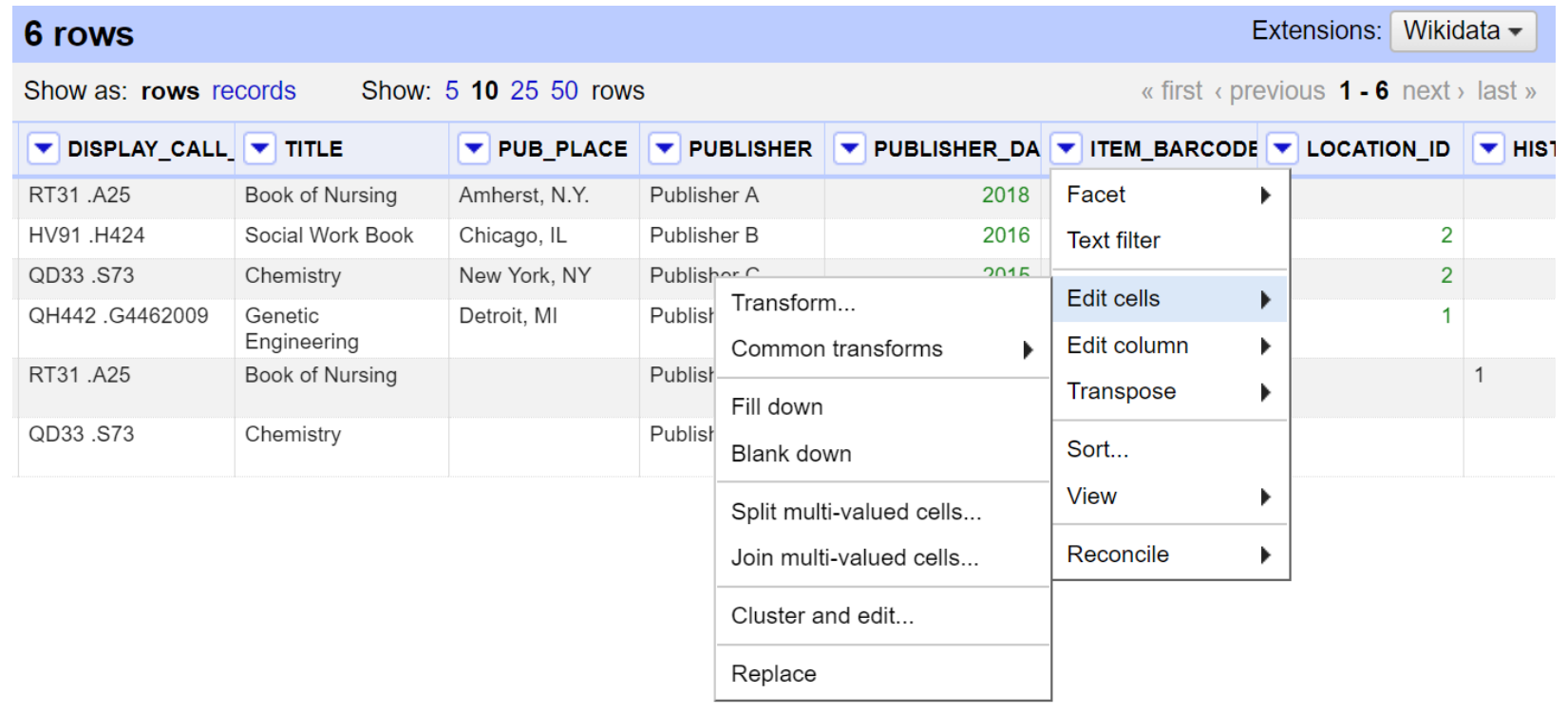

Figure 6: Screenshot of preparing ITEM_BARCODE data. 




Figure 7: Screenshot of transforming ITEM_BARCODE data.

Next, I want to find the values that are not duplicates. I select "Facet," "Customized facets" and "Duplicates facet" on ITEM_BARCODE. I select "false" in the ITEM_BARCODE box on the left-hand side. This will find all items that do not have a duplicate in the same column. After selecting "false," only the non-duplicated items will show (Figures 8-10).

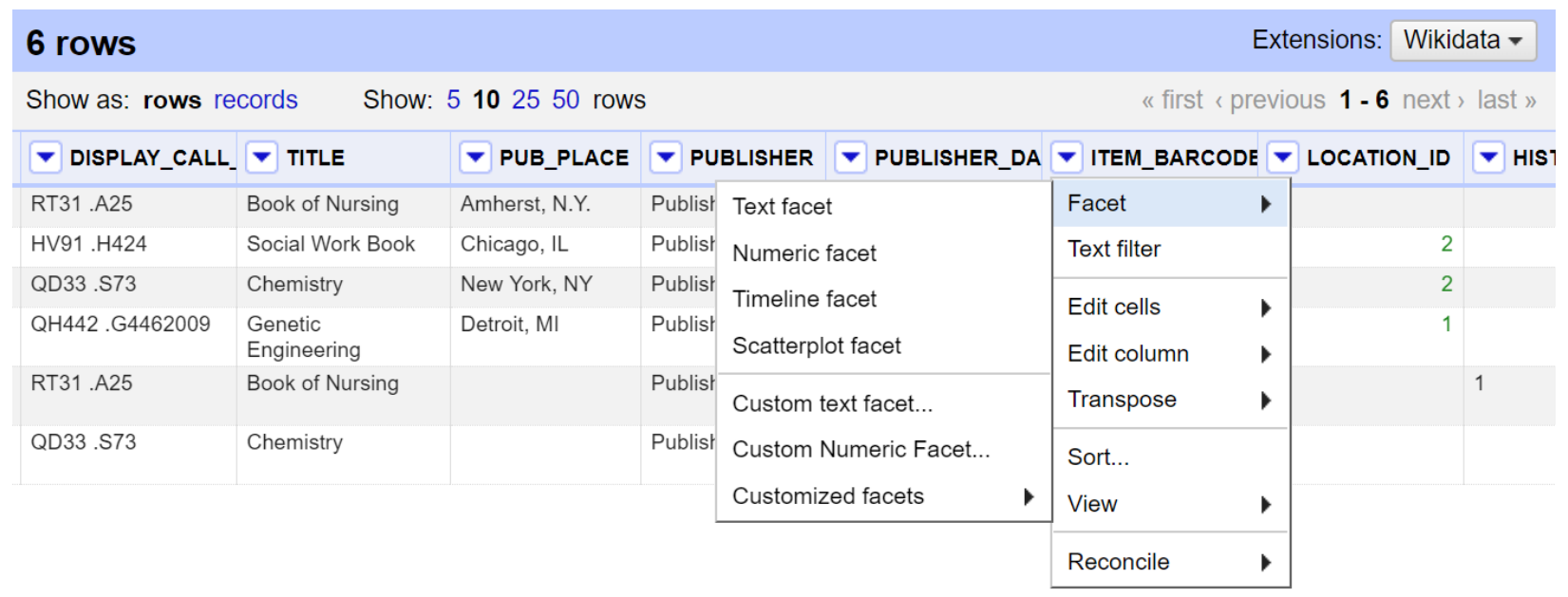

Figure 8: Screenshot of selecting the type of facet in ITEM_BARCODE. 


\begin{tabular}{|c|c|c|c|c|c|c|c|c|}
\hline malink & Word facet & & & & Open... & Export - & \multicolumn{2}{|c|}{ Help } \\
\hline 6 rows & Duplicates facet & \multicolumn{7}{|c|}{ Extensions: Wikidata - } \\
\hline Show as: rows $r$ & Numeric log facet & \multicolumn{7}{|c|}{ «first 〈previous $\mathbf{1}$ - $\mathbf{6}$ next 〉 last » } \\
\hline$\nabla$ DISPLAY_CALI & 1-bounded numeric log facet & BLISHER & $\nabla$ PUBLISHER_DA & $\nabla$ ITEM_BARC & OODE $\nabla$ & LOCATION_ID & $\nabla$ & HIS 1 \\
\hline RT31 .A25 & Text length facet & \multicolumn{2}{|c|}{ Text facet } & Facet & $\triangleright$ & & & \\
\hline HV91 .H424 & Log of text length facet & \multirow{2}{*}{\multicolumn{2}{|c|}{ Numeric facet }} & Text filter & & 2 & & \\
\hline QD33 .S73 & Unicode char-code facet & & & \multirow{3}{*}{$\begin{array}{l}\text { Edit cells } \\
\text { Edit column } \\
\text { Transpose }\end{array}$} & \multirow{2}{*}{ 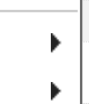 } & 2 & & \\
\hline QH442 .G4462009 & Facet by error & \multicolumn{2}{|c|}{$\begin{array}{l}\text { Timeline facet } \\
\text { Scatterplot facet }\end{array}$} & & & 1 & & \\
\hline RT31 .A25 & Facet by null & \multirow{2}{*}{\multicolumn{2}{|c|}{$\begin{array}{l}\text { Custom text facet... } \\
\text { Custom Numeric Facet... }\end{array}$}} & & 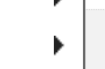 & & 1 & \\
\hline \multirow[t]{3}{*}{ QD33 .S73 } & Facet by empty string & & & \multicolumn{2}{|l|}{ Sort... } & & & \\
\hline & Facet by blank (null or empty string) & \multicolumn{2}{|c|}{ Customized facets } & View & 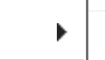 & & & \\
\hline & & & & Reconcile & $\triangleright$ & & & \\
\hline
\end{tabular}

Figure 9: Screenshot of faceting ITEM_BARCODE by duplicates.

\begin{tabular}{|c|c|c|c|c|c|c|c|c|c|c|c|c|c|}
\hline \multirow{3}{*}{$\begin{array}{l}\text { Facet / Filter } \\
\text { Refresh } \\
\text { × ITEM_BARCC }\end{array}$} & \multicolumn{3}{|c|}{ Undo / Redo $2 / 2$} & \multicolumn{8}{|c|}{2 matching rows (6 total) } & Extensions: & Wikidata - \\
\hline & & Reset All & Remove All & \multicolumn{4}{|c|}{ Show as: rows records } & \multicolumn{4}{|c|}{ Show: 5102550 rows } & \multicolumn{2}{|c|}{ «first ( previous $\mathbf{1 - 2}$ next , last » } \\
\hline & DDE & chan & ge invert reset & $\nabla$ & All & & - DISPLAY_CALL_. & $\nabla$ TITLE & - PUB_PLACE & PUBLISHER & - PUBLISHER_DA & $\nabla$ ITEM_BARCODE & LOCATION. \\
\hline \multicolumn{4}{|c|}{2 choices Sort by: name count } & $\hat{z}$ & 5 & 2. & HV91.H424 & Social Work Book & Chicago, IL & Publisher B & 2016 & 987654 & \\
\hline false 2 & & & exclude & & 5 & 4. & QH442.G4462009 & $\begin{array}{l}\text { Genetic } \\
\text { Engineering }\end{array}$ & Detroit, MI & Publisher B & 2019 & & \\
\hline \multicolumn{14}{|l|}{ true 4} \\
\hline \multicolumn{14}{|c|}{ Facet by choice counts } \\
\hline
\end{tabular}

Figure 10: Screenshot of "false" selection of ITEM_BARCODE duplicates.

After selecting "false" to find all items that do not have a duplicate, I navigate to the All column with stars. I then select "Edit rows" and "Star rows," and then close the ITEM BARCODE box on the left-hand side (Figures 11-12). Closing the ITEM_BARCODE box will display all the data while maintaining the stars on the non-duplicated data (Figure 13).

\begin{tabular}{|c|c|c|c|c|c|c|c|c|c|c|c|c|}
\hline \multirow{3}{*}{$\begin{array}{l}\text { Facet / Filter } \\
\text { Refresh } \\
\text { × ITEM_BARC }\end{array}$} & \multicolumn{3}{|c|}{ Undo / Redo 6 / 6} & \multicolumn{7}{|c|}{2 matching rows (6 total) } & Extensions: & Wikidata - \\
\hline & & Reset All & Remove All & \multicolumn{3}{|c|}{ Show as: rows records } & \multicolumn{4}{|c|}{ Show: 5102550 rows } & \multicolumn{2}{|c|}{ «first (previous $\mathbf{1}$ - $\mathbf{2}$ next ) last " } \\
\hline & DE & chan & ge invert reset & - All & DISPL & LAY_CALL_. & - TITLE & - PUB_PLACE & P PUBLISHER & - PUBLISHER_DA & - ITEM_BARCODE & - LOCATION. \\
\hline \multicolumn{4}{|c|}{2 choices Sort by: name count } & \multicolumn{2}{|l|}{ Transform } & 24 & Social Work Book & Chicago, IL & Publisher B & 2016 & 987654 & \\
\hline \multirow{4}{*}{\multicolumn{2}{|c|}{$\begin{array}{l}\text { false } 2 \\
\text { true } 4 \\
\text { Facet by choice counts }\end{array}$}} & \multirow{4}{*}{\multicolumn{2}{|c|}{ exclude }} & Facet & - & \multirow{2}{*}{\multicolumn{2}{|c|}{$\begin{array}{l}\text { Facet by star } \\
\text { Facet by flag }\end{array}$}} & MI & Publisher B & 2009 & & \\
\hline & & & & \multirow{2}{*}{$\begin{array}{l}\text { Edit rows } \\
\text { Edit columns }\end{array}$} & \multirow{2}{*}{, } & & & & & & & \\
\hline & & & & & & & & & & & & \\
\hline & & & & View & • & & & & & & & \\
\hline
\end{tabular}

Figure 11: Screenshot of starring row in All column.

\begin{tabular}{|c|c|c|c|c|c|c|c|c|c|c|c|c|c|}
\hline \multirow{2}{*}{$\begin{array}{l}\text { Facet / Filter } \\
\text { Refresh }\end{array}$} & \multicolumn{3}{|c|}{ Undo / Redo $3 / 3$} & \multicolumn{8}{|c|}{2 matching rows ( 6 total) } & Extensions: & Wikidata - \\
\hline & & Reset All & Remove All & \multicolumn{4}{|c|}{ Show as: rows records } & \multicolumn{4}{|c|}{ Show: 5102550 rows } & \multicolumn{2}{|c|}{ "first < previous 1 - 2 next, last " } \\
\hline \multicolumn{2}{|c|}{ X ITEM_BARCODE } & chan & nge invert reset & $\nabla$ & All & & - DISPLAY_CALL. & -7 TITLE & - PUB_PLACE & PUBLISHER & - PUBLISHER_DA & - ITEM_BARCODE & - LOCATION \\
\hline \multicolumn{4}{|c|}{2 choices Sort by: name count } & $\sum t$ & 5 & 2. & HV91.H424 & Social Work Book & Chicago, IL & Publisher B & 2016 & 987654 & \\
\hline false 2 & & & exclude & $\hat{s}$ & 5 & 4. & QH442, G4462009 & $\begin{array}{l}\text { Genetic } \\
\text { Engineering }\end{array}$ & Detroit, MI & Publisher B & 2019 & & \\
\hline \multicolumn{14}{|l|}{ true 4} \\
\hline \multicolumn{14}{|c|}{ Facet by choice counts } \\
\hline
\end{tabular}

Figure 12: Screenshot of selected starred rows. 


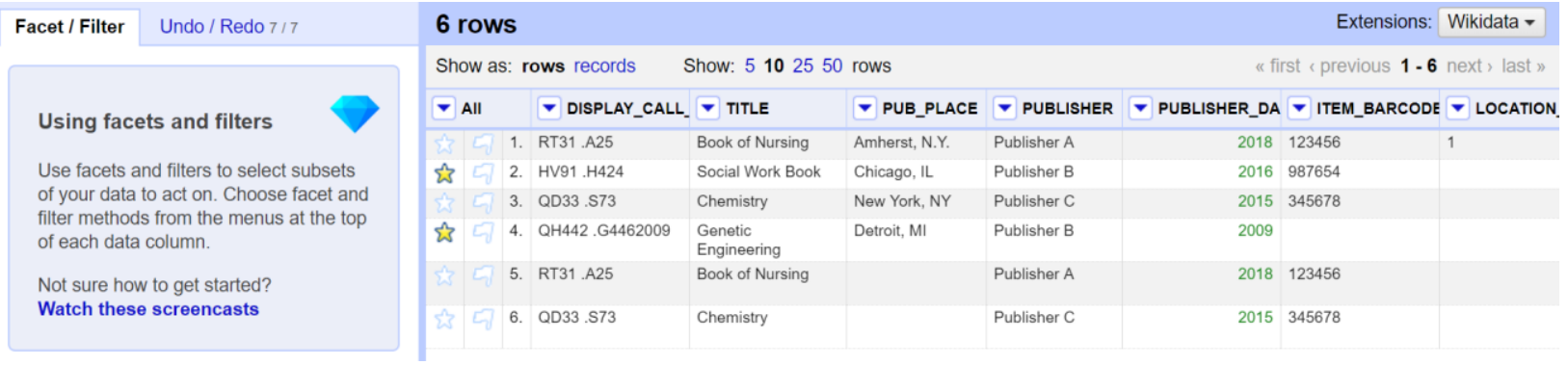

Figure 13: Screenshot of selected data starred within all data.

\section{Selecting all Duplicates \& 'Starring' Certain Items}

Next I want to select all duplicated items and star only those items which contain LastOfCHARGE_DATE data. To do this, I select "Facet," "Customized facets," and "Facet by blank (null or empty string)" on the LastOfCHARGE_DATE column (Figures 14-15).

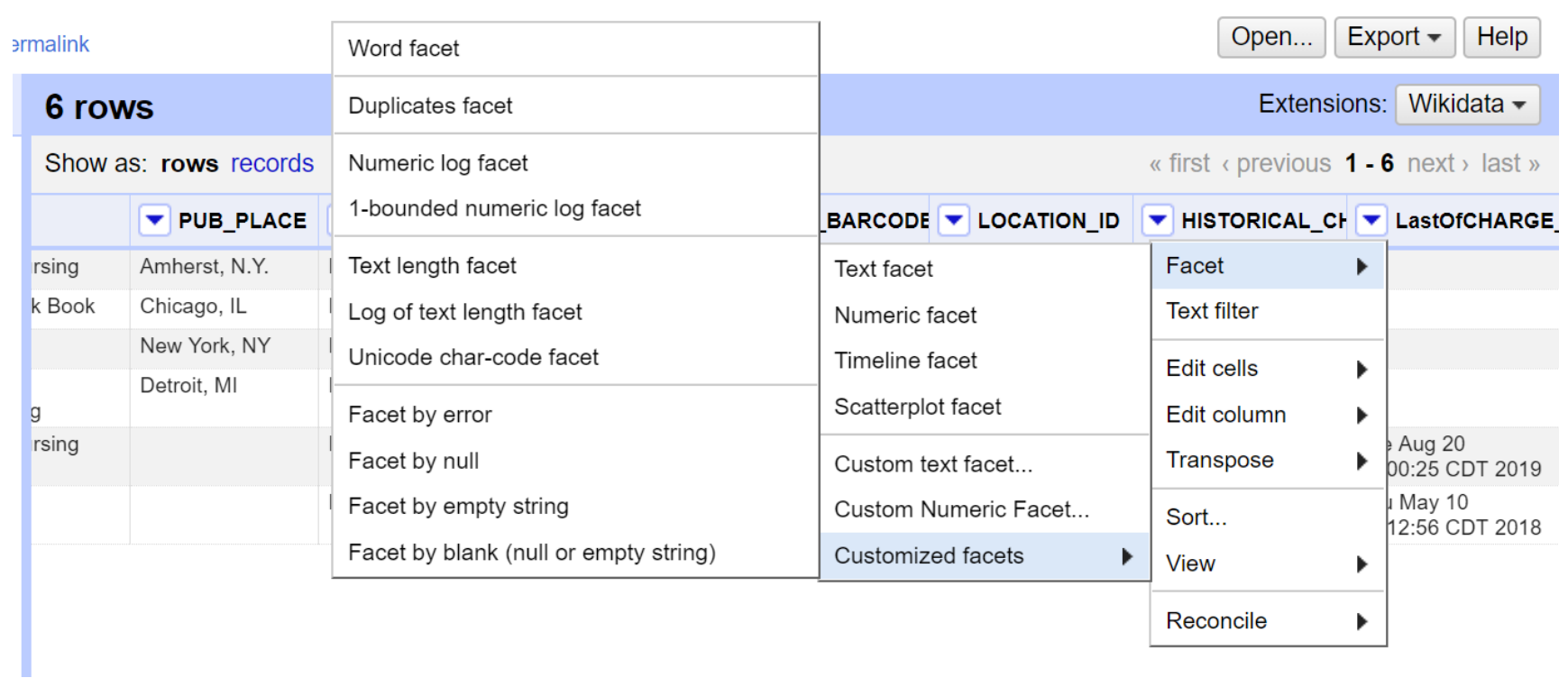

Figure 14: Screenshot of selecting the type of facet in LastOfCHARGE_DATE.

\begin{tabular}{|c|c|c|c|c|c|c|c|c|c|c|}
\hline \multirow{2}{*}{$\begin{array}{l}\text { Facet / Filter } \\
\text { Refresh }\end{array}$} & \multicolumn{2}{|l|}{ Undo / Redo $7 / 7$} & \multicolumn{6}{|c|}{6 rows } & \multicolumn{2}{|c|}{ Extensions: Wikidata - } \\
\hline & Reset All & Remove All & \multicolumn{2}{|c|}{ Show as: rows records } & \multicolumn{4}{|c|}{ Show: 5102550 rows } & \multicolumn{2}{|c|}{ « first (previous $\mathbf{1}-\mathbf{6}$ next, last » } \\
\hline \multicolumn{2}{|c|}{$X$ LastOfCHARGE_DATE } & change & & - PUB_PLACE & - PUBLISHER & - PUBLISHER_DA & - ITEM_BARCODE & - LOCATION_ID & HISTORICAL_Cr & LastofCHARGE \\
\hline \multirow{2}{*}{\multicolumn{3}{|c|}{2 choices Sort by: name count }} & rsing & Amherst, N.Y. & Publisher A & 2018 & 123456 & 1 & & \\
\hline & & & k Book & Chicago, IL & Publisher B & 2016 & 987654 & 2 & & \\
\hline \multirow{2}{*}{\multicolumn{3}{|c|}{$\begin{array}{l}\text { false } 2 \\
\text { true } 4\end{array}$}} & & New York, NY & Publisher C & 2015 & 345678 & 2 & & \\
\hline \multirow{3}{*}{\multicolumn{3}{|c|}{ Facet by choice counts }} & g & Detroit, MI & Publisher B & 2009 & & 1 & & \\
\hline & & & rsing & & Publisher A & 2018 & 123456 & & 1 & $\begin{array}{l}\text { Tue Aug } 20 \\
\text { 15:00:25 CDT } 2019\end{array}$ \\
\hline & & & & & Publisher C & 2015 & 345678 & & 3 & $\begin{array}{l}\text { Thu May } 10 \\
\text { 13:12:56 CDT } 2018\end{array}$ \\
\hline
\end{tabular}

Figure 15: Screenshot of "false" selection of LastOfCHARGE_DATE.

I want the items that are not blank, and so I select "false." After selecting "false" to find all items that have information in the LastOfCHARGE_DATE column, I navigate to the All column with stars. I select "Edit rows" and "Star rows," and then close the LastOfCHARGE_DATE box (Figures 16-17). Closing this box will display all the data while maintaining the stars on the nonduplicated data and the duplicated item lines with LastOfCHARGE_DATE data (Figure 18). 


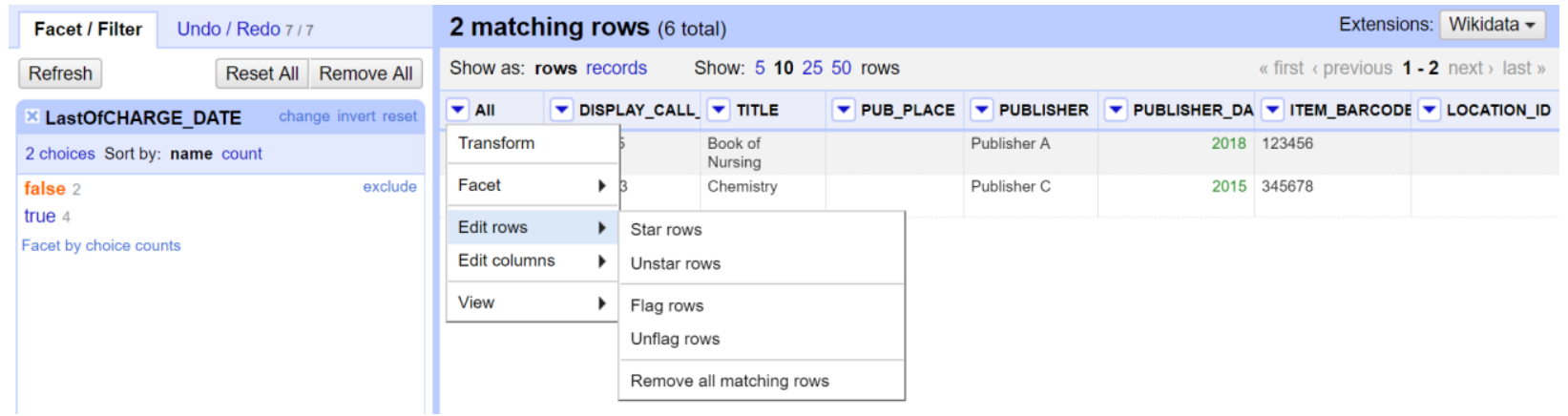

Figure 16: Screenshot of starring row in All column.

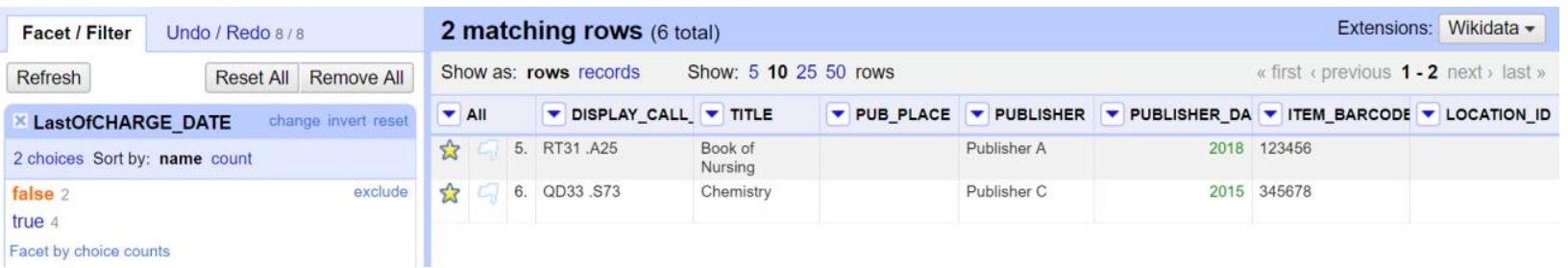

Figure 17: Screenshot of selected starred rows.

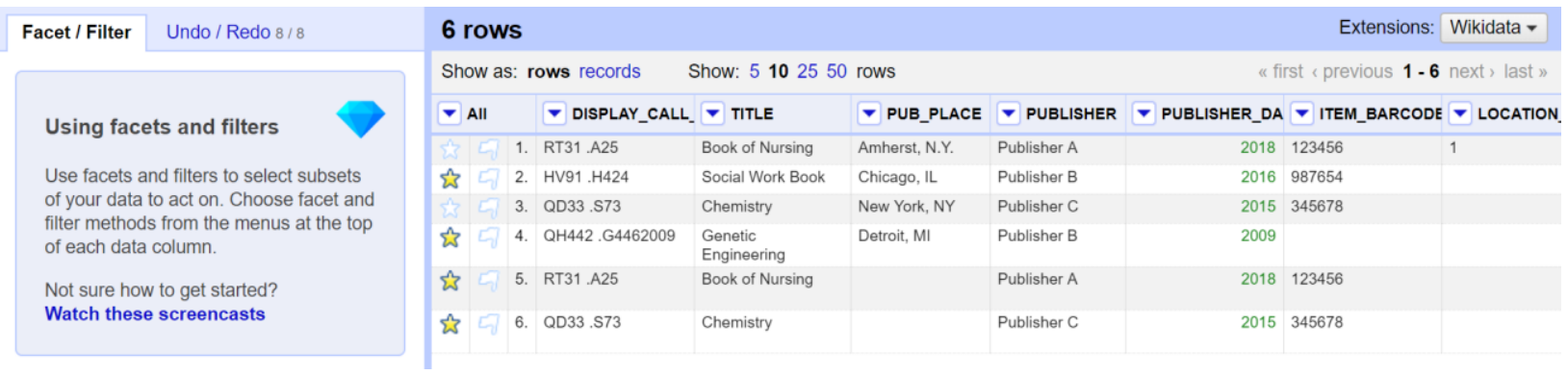

Figure 18: Screenshot of selected data starred within all data.

\section{Ensuring All Data are Included}

Then, I want to ensure that I have included all data. It is possible that I did not have a barcode number for all items. In my example, the single blank barcode was detected when I looked for duplicated items. However, if you have multiple blank barcode items, this would have been overlooked. To check for blank barcodes, select "Facet," "Customized facets" and "Facet by blank (null or empty string)" on the ITEM_BARCODE column (Figures 19-20). 


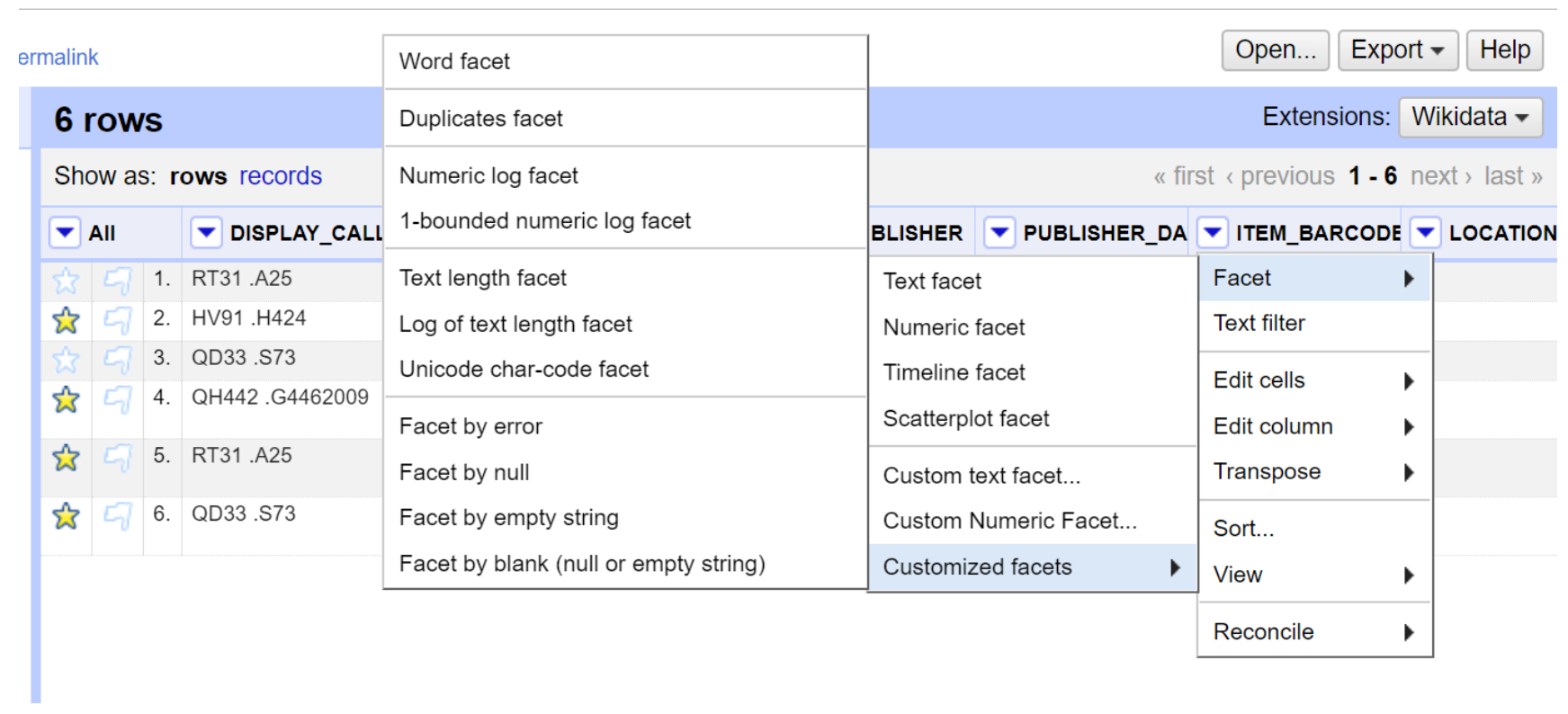

Figure 19: Screenshot of selecting the type of facet in ITEM_BARCODE.

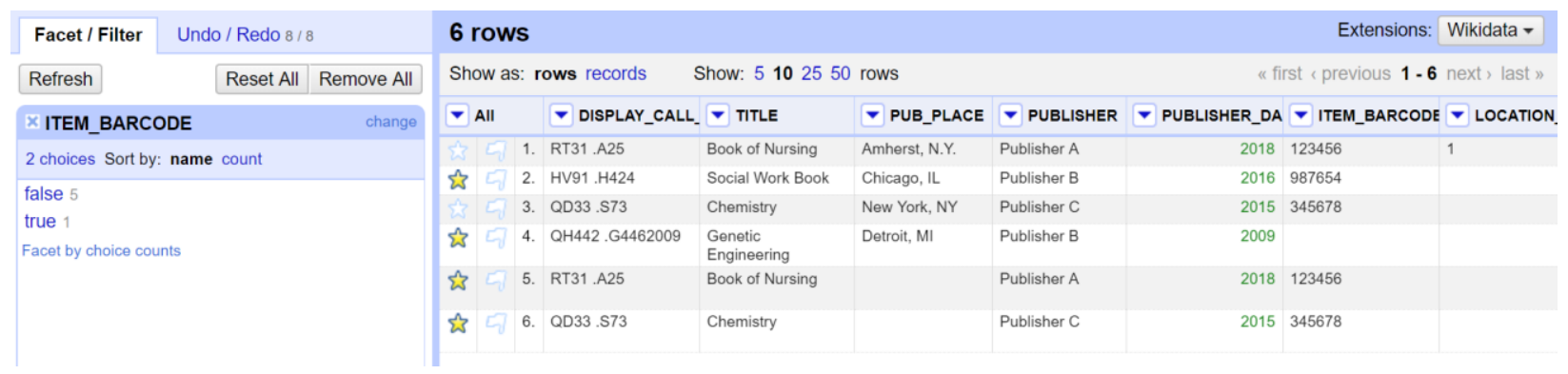

Figure 20: Screenshot of "true" selection of ITEM_BARCODE.

In this case, I want to select "true" because I am looking for blank barcode lines. Again, select "Edit rows" and "Star rows," and then close the ITEM_BARCODE box (Figures 21-22). Closing this box will display all the data while maintaining the stars on the non-duplicated data, the duplicated item lines with ITEM_BARCODE data, and any items without barcodes (Figure 23).

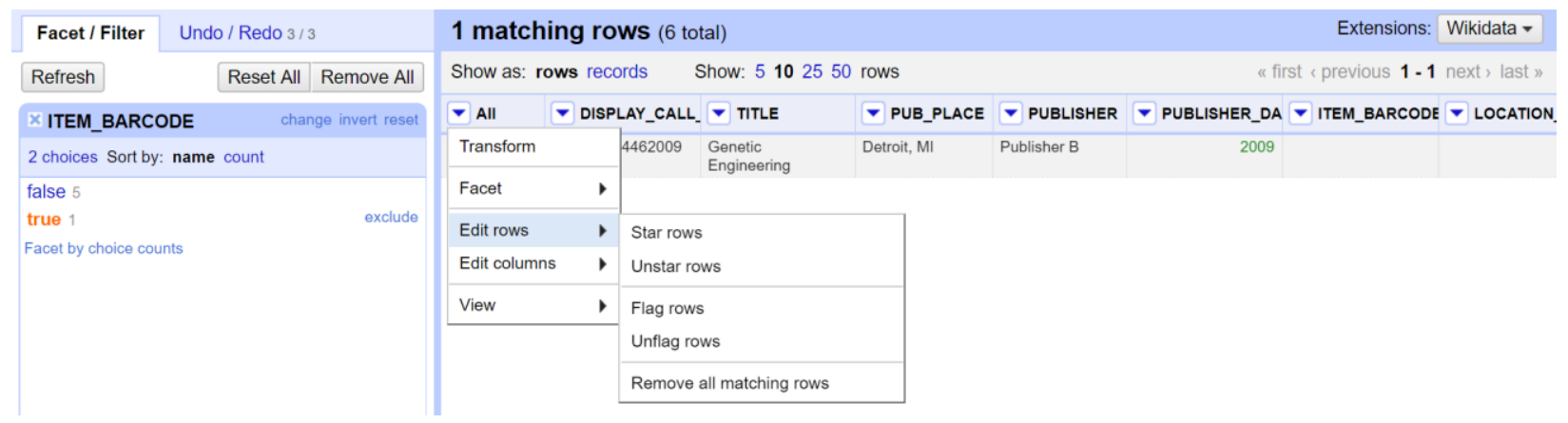

Figure 21: Screenshot of starring row in All column. 


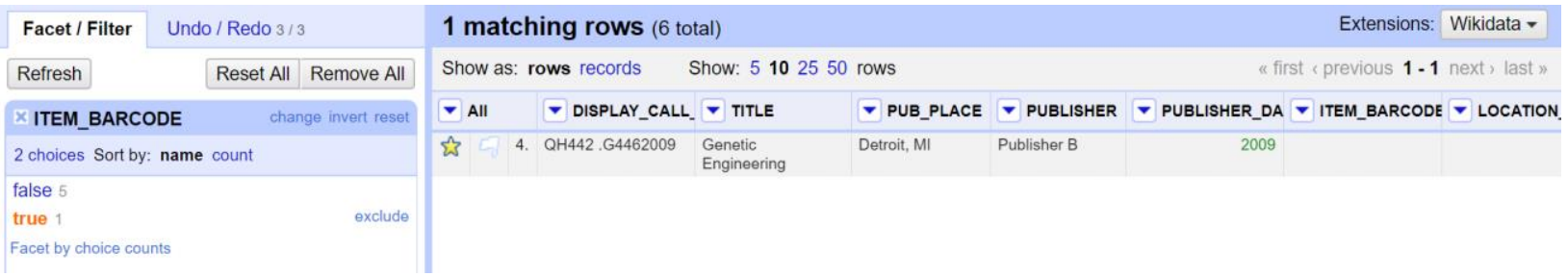

Figure 22: Screenshot of selected starred rows.

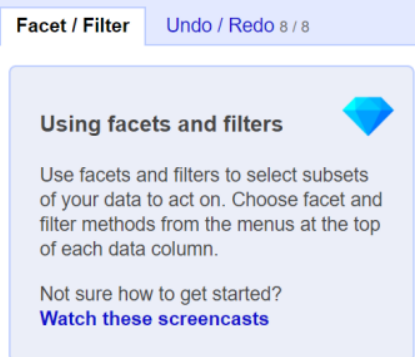

\begin{tabular}{|c|c|c|c|c|c|c|c|c|c|c|}
\hline \multicolumn{8}{|c|}{6 rows } & \multicolumn{2}{|r|}{ Extensions: } & \multirow{2}{*}{$\begin{array}{l}\text { Wikidata }= \\
\text { next, last » }\end{array}$} \\
\hline \multicolumn{4}{|c|}{ Show as: rows records } & \multicolumn{4}{|c|}{ Show: 5102550 rows } & \multicolumn{2}{|c|}{ « first \& previous 1 - 6} & \\
\hline$\nabla$ & All & & DISPLAY_CALL_. & title & - PUB_PLACE & - PUBLISHER & PUBLISHE & ER_DA & - ITEM_BARCODE & LOCATION. \\
\hline हt? & 5 & 1. & RT31.A25 & Book of Nursing & Amherst, N.Y. & Publisher A & & 2018 & 123456 & 1 \\
\hline$\hat{s}$ & 57 & 2. & HV91 .H424 & Social Work Book & Chicago, IL & Publisher B & & 2016 & 987654 & \\
\hline है & 57 & 3. & QD33.S73 & Chemistry & New York, NY & Publisher C & & 2015 & 345678 & \\
\hline $\boldsymbol{s}$ & 57 & 4. & QH442 .G4462009 & $\begin{array}{l}\text { Genetic } \\
\text { Engineering }\end{array}$ & Detroit, MI & Publisher B & & 2009 & & \\
\hline 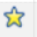 & 5 & 5. & RT31.A25 & Book of Nursing & & Publisher A & & 2018 & 123456 & \\
\hline$\hat{s}$ & 5 & 6. & QD33.S73 & Chemistry & & Publisher C & & 2015 & 345678 & \\
\hline
\end{tabular}

Figure 23: Screenshot of selected data starred within all data.

\section{Selecting Only "Starred" Items}

Next, I want to select only the data that have been marked with a star. This includes all items that have no barcodes, do not have a duplicate, and duplicated items with the historical charge information. To do this, select "Facet" and "Facet by star" on the All column with stars (Figure 24). Then select "true" (Figures 25-26). This will display all the desired items.

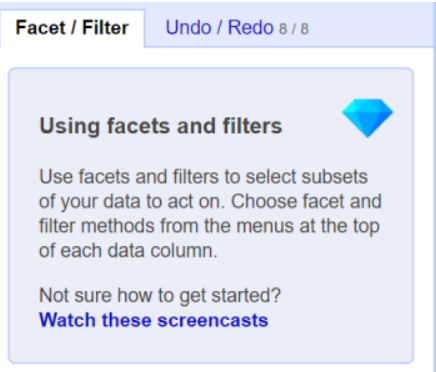

\begin{tabular}{|c|c|c|c|c|c|c|c|c|c|}
\hline \multicolumn{7}{|l|}{6 rows } & \multicolumn{2}{|r|}{ Extensions: } & \multirow{2}{*}{$\begin{array}{l}\text { Wikidata - } \\
\text { next, last ” }\end{array}$} \\
\hline \multicolumn{3}{|c|}{ Show as: rows records } & Show: 51025 & rows & & & \multicolumn{2}{|c|}{ "first (previous $\mathbf{1}-\mathbf{6}$ next, last » } & \\
\hline All & DISP & AY_CALL_ & TitLe & - PUB_PLACE & PUBLISHER & PUBLISHE & ER_DA & ITEM_BARCODE & LOCATION. \\
\hline \multicolumn{2}{|l|}{ Transform } & & Book of Nursing & Amherst, N.Y. & Publisher A & & 2018 & 123456 & 1 \\
\hline Facet & , & \multirow{2}{*}{\multicolumn{2}{|c|}{ Facet by star }} & po, IL & Publisher B & & 2016 & 987654 & \\
\hline & & & & ork, NY & Publisher C & & 2015 & 345678 & \\
\hline \multirow{3}{*}{$\begin{array}{l}\text { Edit rows } \\
\text { Edit columns }\end{array}$} & • & \multicolumn{2}{|c|}{ Facet by flag } & MI & Publisher B & & 2009 & & \\
\hline & s & & Engineering & & & & & & \\
\hline & $b$ & & Book of Nursing & & Publisher A & & 2018 & 123456 & \\
\hline View & ・ & & Chemistry & & Publisher C & & 2015 & 345678 & \\
\hline
\end{tabular}

Figure 24: Screenshot of selecting the type of facet in All.

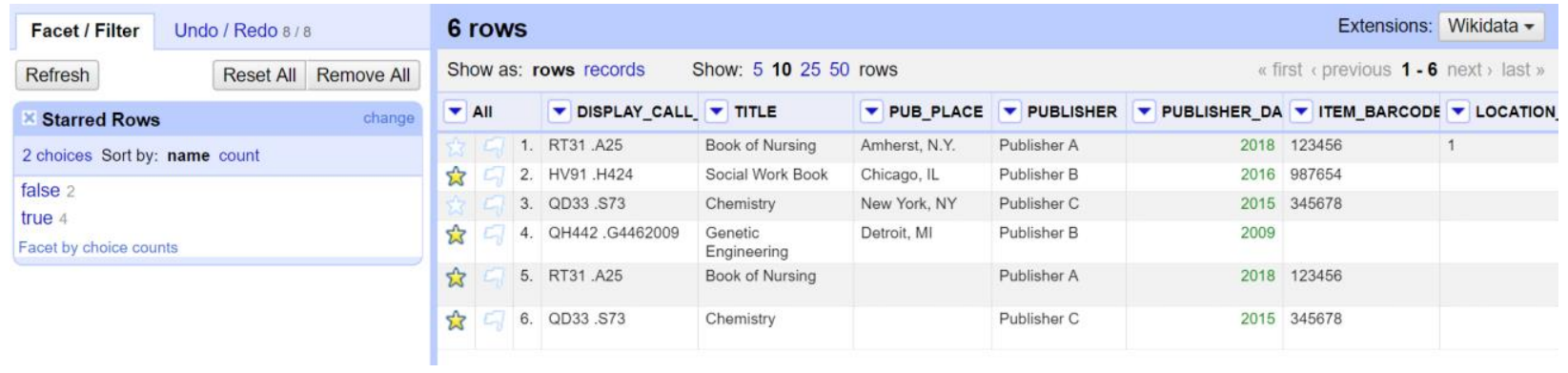

Figure 25: Screenshot of selected starred rows. 


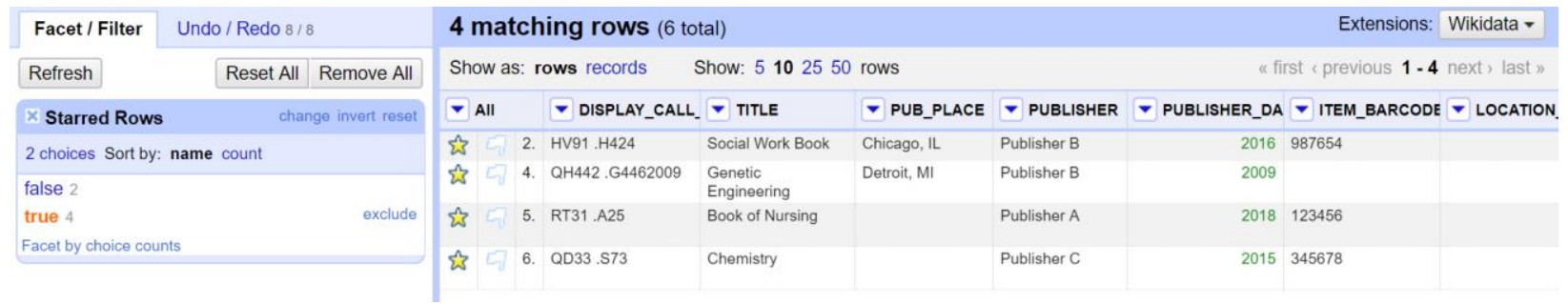

Figure 26: Screenshot of selected data starred.

\section{Almost Done! Exporting Data}

Finally, you can export your data into many different forms. Do not close the "Starred Rows" box. Select "Export" in the upper right hand corner and select your desired format (Figure 27). I'll use the Excel format (Figure 28). Once in Excel, I prefer to format columns, e.g. wrapping text, in order to make the table more visually pleasing.

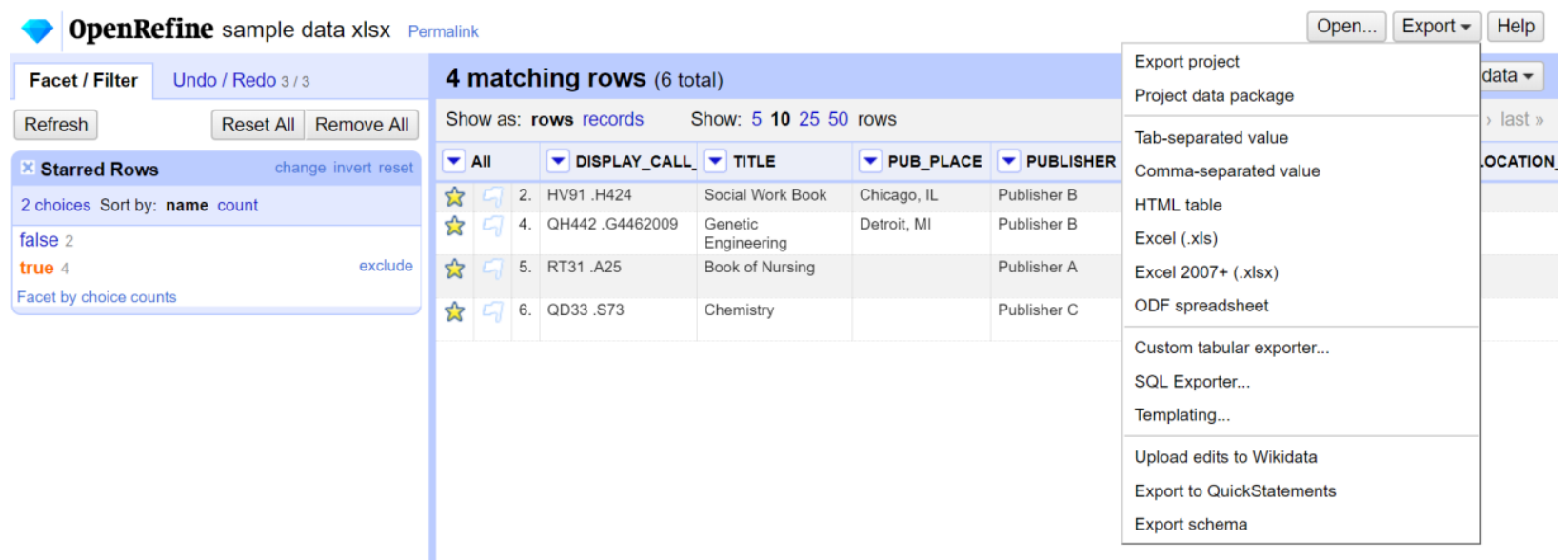

Figure 27: Screenshot of Export options.

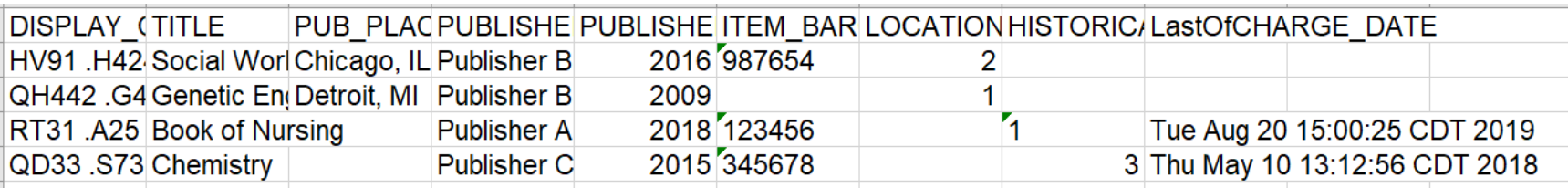

Figure 28: Screenshot of exported data from OpenRefine.

\section{Conclusion}

With these few steps, I have used the facet row feature to ensure that I have kept the correct duplicate line with the historical charge information while also ensuring that I have kept nonduplicated items or items without barcodes in the file. OpenRefine has free online courses available (OpenRefine), and other articles provide detailed descriptions of how to get and use OpenRefine (Groves 2016; Hill 2016). I used this method as part of the weeding project, but it could be applied to any situation with duplicated data. After completing this process, I have effectively and quickly deleted selected duplicated information to improve my workflow during the deselection process. 


\section{References}

Groves, A. 2016. Beyond Excel: how to start cleaning data with OpenRefine. Multimedia Information \& Technology 42(2): 18-22.

Hill, K.M. 2016. In search of useful collection metadata: using OpenRefine to create accurate, complete, and clean title-level collection information. Serials Review 42(3): 222-228. DOI: 10.1080/00987913.2016.1214529.

OpenRefine [Internet]. [cited 2019 July 15]. Available from http://openrefine.org/documentation.html

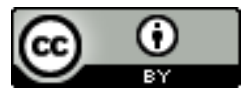

This work is licensed under a Creative Commons Attribution 4.0 International License. 